\title{
Determinants of ICO Investment Decision: An Exploratory Factor Analysis
}

\author{
Nurettin Ayarc1 ${ }^{1} \&$ Ayşe Özden Birkan ${ }^{2}$ \\ ${ }^{1}$ ec4u expert consulting ag, Münich, Germany \\ 2 Department of Economics, Faculty of Business, Yaşar University, İzmir, Turkey \\ Correspondence: Ayşe Özden Birkan, Department of Economics, Faculty of Business, Yaşar University, Üniversite \\ Cad. No: 37-39, Bornova, İzmir, Turkey. Tel: 90-232-570-8941. E-mail: ozden.birkan@ yasar.edu.tr
}

Received: July 3, 2020

Accepted: August 26, 2020

Online Published: September 21, 2020

doi:10.5430/ijfr.v11n5p69

URL: https://doi.org/10.5430/ijfr.v11n5p69

\begin{abstract}
An Initial Coin Offering (ICO) is a funding mechanism used by projects to sell their crypto-token in exchange for Bitcoin, Ether, etc. It is the counterpart of the Initial Public Offering in the new digital currency economy. ICOs help projects to be funded in a short time with a high-profit margin.

The primary purpose of this study is isolating the principal factors that affect the decision to invest in an ICO. A large array of potential signals, consisting of promotion and marketing effects, investor motivation, founder team effects, whitepaper and ICO specific factors, are considered in an online survey and the responses are analyzed using Exploratory Factor Analysis.

The results of the analysis reveal five composite principal factors that determine the decision to invest in an ICO. These five principal factors are the ICO whitepaper, websites for finance news and ICO listings, ICO project sector and founder, ICO project team and social media. Our findings provide a perspective to both investor and ICO founders about which factors to prioritize when deciding to launch an ICO or to invest in one.
\end{abstract}

Keywords: cryptocurrency, ICO, initial coin offering, digital currency, exploratory factor analysis

\section{Introduction}

2008 was a memorable year not only because of the global financial crisis but also because the first peer-to-peer decentralized cryptocurrency called Bitcoin was introduced (Chuen, 2015). Bitcoin was announced on mailing lists and published as a whitepaper by the unknown person who uses the nickname "Satoshi Nakamoto". The purpose of Bitcoin was defined as decentralizing the payment system to create irreversible transactions. In the whitepaper, Nakamoto describes the need for Bitcoin with the following sentences:

"What is needed is an electronic payment system based on cryptographic proof instead of trust, allowing any two willing parties to transact directly with each other without the need for a trusted third party. Transactions that are computationally impractical to reverse would protect sellers" (Nakamoto, 2008)

The revolution, which started with Bitcoin, has been followed by thousands of alternative tokens, which are designed for different purposes from financial services to e-commerce, communication, and many more. With the introduction of the ERC20 technology, it has become even easier to structure new projects, and this has helped Initial Coin Offering (ICO) strategy to become common practice among startup founders.

First ICO was launched by Mastercoin in 2013. Purpose of this coin was allowing Bitcoin users to generate smart contracts without leaving the Bitcoin set up (Willett, 2012). Inspired by the quickly raised funds, many startups announced their own token (Boreiko and Sahdev, 2018). Investing in ICOs has become a trend as people got exposed to more news and knowledge on cryptocurrencies and blockchain technology.

The term ICO is derived from the IPO (Initial Public Offering), which defines the method that enables well-established companies to raise capital (Jaffe, 2018). ICO is a strategy used by crypto-affiliated companies, which plan to launch a new token-based utility or service funded by the investors. 
In this study, a comprehensive list of potential elements, which can impact the decision of the ICO investors, is developed. Instead of focusing on a specific set of aspects, this study aims to cover as many potential determinants of ICO investment as possible. The ICO investing signals we consider consist of promotion and marketing effects, investor motivation, founder team effects, whitepaper and ICO specific factors. The following section provides an overview of these factors and how they are expected to be relevant for the decision to invest in an ICO. Then we present the exploratory factor analysis of the data collected by our online survey. Conclusions follow.

\section{Factors Potentially Relevant for ICO Investments}

\subsection{Promotion and Marketing Effects}

\subsubsection{Social Media Channels}

The use of social media during the ICO process provides some benefits to both investors and the ICO team. Companies have a chance to create their community and inform their user about the latest news and promotion about their product. For the investors, social media means sharing an experience, building a community and sharing feedback. Another critical aspect of social media is that they can provide many metrics like the number of followers, Likes, Shares, etc.

\subsubsection{ICO Communities}

Cryptocurrency communities, chat groups also have a role in the success of an ICO. While some ICOs use their community chat group as a marketing platform, it is also possible to utilize these platforms as a customer support portal. Messaging channels like Telegram and Slack enable companies to give fast around the clock support to community members from different time zones. ICO communities also allow members to send their feedback and ask questions to community managers and other members of the group, allowing the user to have a feeling of being part of the team.

\subsubsection{Friends Effect}

Friends and relatives have an impact on the many decisions we have and ICO investment decision may be one of them. People may tend to invest in ICOs, which they hear from their friends or relatives.

\subsubsection{Social Guru and Influencers Effect}

An influencer is one of the marketing forms where the focus is placed on an individual in order to influence the buyers. Since the lines between the genuine and paid promotion of the product has become harder to distinguish with the rise of social media, influencer marketing gained significant power (Woods, 2016).

\subsubsection{ICO Listing Websites}

The most significant advantage of ICO listing websites is seen as the target audience. Unlike the other channels, ICO listing websites already have a quality audience who is looking for the next ICO to invest. Most of the listing websites have standard functionality like announcing the ICOs and their basic information (hard cap, soft cap, ICO price, founder and teams) some of them also provide detailed reviews and a scoring system.

\subsubsection{News Websites and Forums}

News websites offer personalized news where an investor will be informed only of specific topics of interest while forums act as a network for the investors where they can discuss the ICO on their own, considering the news and come up with new opinions and decisions.

\subsection{Investor Motivation}

Issues related to investor motivation can be discussed under four headings; project idea, utility value of the token, pump and dump versus long term investing.

\subsubsection{Project Idea}

Most of the ICOs are promising to revolutionize a particular type of industry. Since the potential and the target group of each industry is different; which industry the ICO is involved in has considerable impact on the decisions of the investors.

\subsubsection{Using the Token as a Utility}

Utility tokens have more purpose than raising funds; they are also designed to be spent in the blockchain ecosystem, which provides quick liquidity. Utility tokens have many uses from peer to peer transaction services to gaming and betting. This purpose-oriented design provides tangible advantages to ICO. (Sockin and Xiong, 2018) 


\subsubsection{Pump and Dump Schemes}

The anonymity cryptocurrency markets provide has expanded the scope of pump and dump practices from traditional investments to cryptocurrencies. While the targets and tactic used in the traditional and Crypto P\&D schemes are very similar, the timescale in crypto markets can be as short as a few minutes ( $\mathrm{Li}$ and Wang, 2019).

\subsubsection{Long Term Investing}

HODL is a slang word used in the crypto community for holding the token instead of selling it. This phrase implies that Bitcoin should be considered as a long-term investment regardless of the short-term fluctuations in its price.

\subsection{Founder Team}

ICO investing has more significant risks than IPO investing, given the existence of only the blueprint and no other physical assets. High-quality projects are expected to disclose information more frequently and be more transparent compared to low-quality projects (de Jong, Roosenboom, and van der Kolk, 2018). Gaining the trust of potential investors increases the chances of larger investments and quicker achievement of the targeted amounts, as well as the rapid inception of the projects. Founder reputation, experience of the team members in cryptocurrencies, the advisors and the partner companies are the building blocks of the trust needed by investors before they can invest their money.

\subsection{Whitepaper}

An ICO whitepaper is a document, which gives details about the problem that ICO tries to solve and how it tries to solve this problem by using the blockchain technology. It is a very important source of information on the quality, competitiveness and potential success of the project. The whitepaper presents information on the aims and strategies of the project, funding of the project, the timetable and the milestones of the project as well as technical information on the token. It also gives information on the size of token supply how the supply will be distributed, when it will be released, and when it will be tradeable on the exchanges.

\subsection{ICO Specific Factors}

\subsubsection{Liquidity}

Liquidity refers to the ability of an institution to convert its physical assets into capital or finances. It may also be deemed to be the ability of a debtor to pay a debt when it falls due. The workings of ICO are dependent on the demand and supply of the virtual currency in the market and not on the existence of physical assets. Thus the liquidity of ICOs is difficult to assess. Primary determinants of the liquidity of the token are price dynamics, buybacks by the ICO owners creating liquidity for the token, burning of the tokens which are bought back, creating scarcity and dividend payments to shareholders.

\subsubsection{Hardcap/Softcap}

Hard cap refers to the maximum amount of capital that can be raised during the ICO. It is the limit above which the amount is returned to the investors. Most ICOs put hard cap values quite high compared to soft cap value. In most of the case, this target cannot be reached during the ICO.

The soft cap is the minimal amount of money that needs to be raised by the ICO for the token to be fully-fledged. The soft cap is an aggregate of the expenses that are incurred in the development and rolling out of the new cryptocurrency. If the soft cap is not reached, the project is terminated, and money is sent back to the investors.

There are also ICOs that do not have any token supply limit, which are called uncapped. This enables everyone to invest in the ICO and allows ICO founders to put extra money in case the project needs additional cash flow.

\subsubsection{The Attitude of Countries Against ICO}

Some countries believe that, as long as they are regulated and carefully supervised, ICOs are not a threat; some countries have a stricter attitude. More regulations and accountability are seen as a way to improve the quality of the ICO ecosystem. However, in some cases, the regulations might also restrict the investors from investing the ICO or decrease the motivation of the investors for the ICOs.

\subsubsection{Taxation and Regulation}

ICO operations across the world correspond to a considerable sum of income and /or capital (Zetzsche, Buckley, Arner, and Föhr, 2017). Absence of regulatory taxation means loss of revenue for the governments and/or misuse of capital. An ICO basically aims to create a virtual currency and finance a project. In order to decide which regulations apply, it is crucial to characterize the token as to whether it is a security, currency or commodity. (Barsan, 2017). 
Depending on this characterization tax rate and tax burden and its distribution as well as the relevant legal framework becomes apparent. The tax regulations put in place make sure ICO investors are not left out of the tax system. The investment capital is also regulated in various countries to avoid monopoly and abnormal market conditions. All these help establish the stability of the ICO investment.

\section{Factor Analysis of Survey Data}

This study aims at determining the factors that are essential in the decision-making process of the ICO investors. In order to extract these factors from the responses to an online survey, exploratory factor analysis is used. The self-administered online survey was carried out over the period of January to April 2019, resulting in 66 responses. Survey participants were found via Facebook groups and Bitcoin forums, primary focus of which is crypto, ICO investment, and Bitcoin. While targeting the related participants, in order to avoid a hypothetical bias, we asked only attendees who are aware of the ICO concept and have invested in an ICO at least once before taking the survey.

From the potential determinants mentioned in Section 2, we have compiled a list of elements that are likely to have an impact on the investment decision. That list is presented in Table 1.

Table 1. Elements used in factor analysis

\begin{tabular}{llll}
\hline No & Element & No & Element \\
\hline E1 & Facebook & E20 & Project sector \\
E2 & Twitter & E21 & Use value of the token \\
E3 & Instagram & E22 & Pump and dump opportunity \\
E4 & Linkedin & E23 & Expected holding period \\
E5 & Slack & E24 & Reputation of founders \\
E6 & Telegram & E25 & Experience of founders in blockchain \\
E7 & Reddit & E26 & Experience of founders in the sector of their ICO \\
E8 & BitcoinForum & E27 & Advisors \\
E9 & Friends and relatives & E28 & Development team \\
E10 & Advise from cryptocurrency gurus & E29 & Marketing team \\
E11 & Number of listing websites for the ICO & E30 & Sales team \\
E12 & Score from the ICO listing website & E31 & Partner companies \\
E13 & Review from the ICO listing website & E32 & Government regulation \\
E14 & Visitor comments on the ICO listing website & E33 & Roadmap \\
E15 & Crypto news website & E34 & Technical features \\
E16 & Finance and economy news website & E35 & Product market fit \\
E17 & General news website & E36 & Founder and team \\
E18 & Personal blogs & E37 & Token distribution \\
E19 & Project idea & E38 & Softcap/Hardcap \\
\hline
\end{tabular}

In the survey, a five-point Likert scale was used with different wordings depending on the context. In order to analyze the collected data, IBM SPSS Statistics 2.0 for Windows has been used. As depicted in Figure 1 (adopted from Ozturkoglu et al., 2016), exploratory factor analysis (EFA) was conducted to analyze the collected data and extract the primary factors. The first two steps of the analysis consist of data collection steps according to predetermined elements. In the third step, correlations and anti-image correlations are scanned, and Kaiser Kaiser-Meyer-Olkin (KMO) and Bartlett's Test statistics are examined. In the fourth step, in order to decide on the significant factors, factor extraction operations are performed. In the fifth step factor loading analysis has been performed using the Varimax method to rotate the component matrix. In the sixth step, reliability analysis has been conducted using Cronbach alpha statistics in order to confirm the consistency of the principal factors that were decided in the 5th step. Then in the $6^{\text {th }}$ step, reliability analysis is conducted using Cronbach's $\alpha$ coefficient and thus the final composite principal factors that affect ICO investment decision are obtained.

In order to perform a factor analysis, the adequacy of the correlation matrix of the collected sample has been confirmed. According to Tabachnick and Fidell (2012), factor analysis is not significant if none of the correlation 
exceeds 0.3. On the other hand, a correlation matrix that consists of high correlation elements signals to significant and justified results. Our data set exhibits large correlation coefficients.

In the anti-image matrix, which is the matrix of the negatives of the partial correlations among elements, the individual KMO Measure of Sampling Adequacy values for some of the elements were lower than 0.5. This shows that these elements appear to lack sufficient correlation with other elements; hence, they should be removed (Hair et al., 2013). Accordingly, elements with the lowest individual KMO values were removed one by one, starting with the lowest value. The elements removed from the analysis in this way are listed in Table 2, along with their KMO values. As the analysis continued, a total of 12 elements were removed, one at a time starting with the lowest loading coefficient because their loading coefficients in the rotated component matrix were less than 0.5. Meanwhile, the general Kaiser-Meyer-Olkin (KMO) Measure of Sampling Adequacy test was checked to see if the data was likely to factor well, at each step.

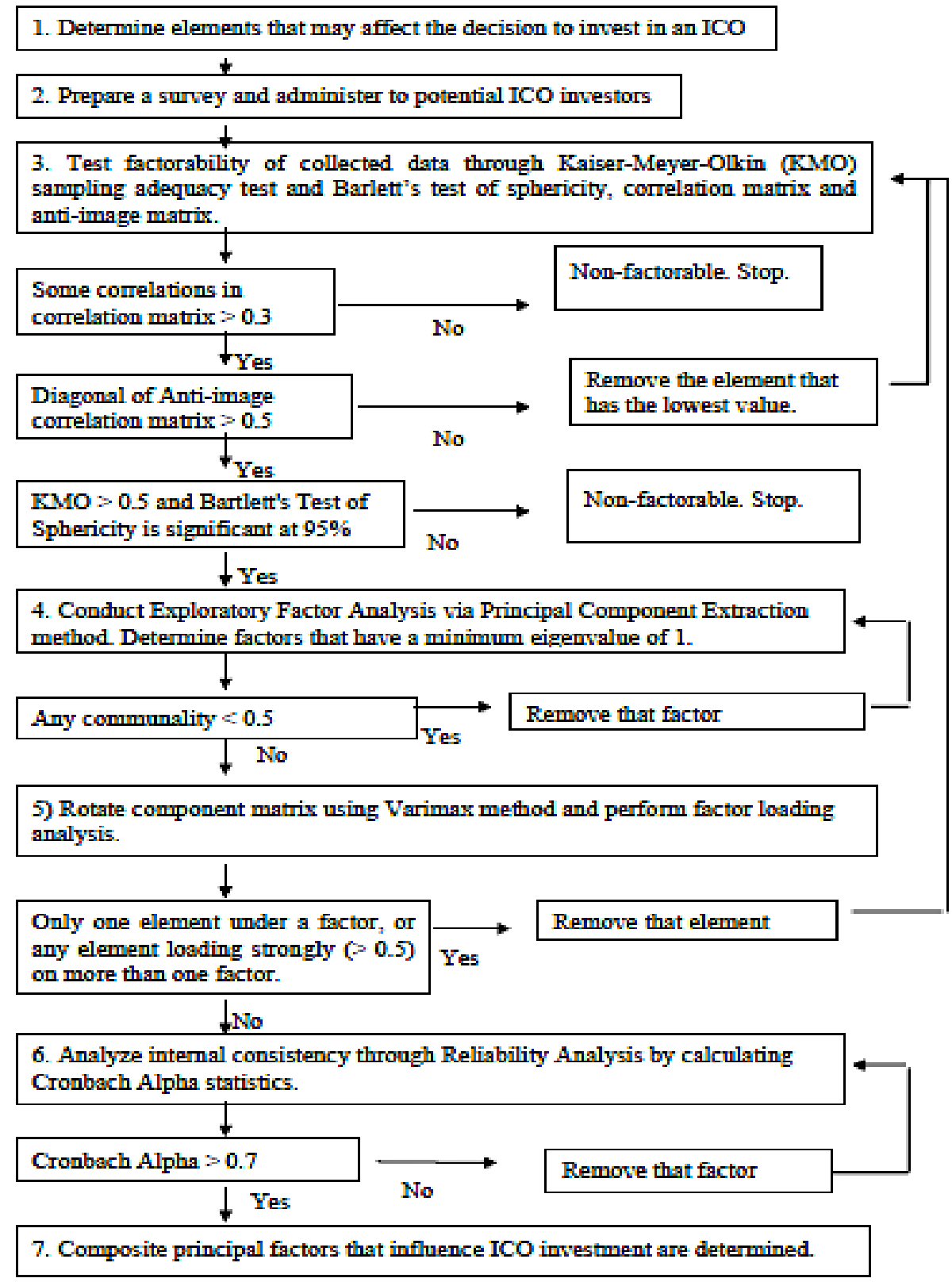

Figure 1. Principal component factor analysis process 
Table 2. Removed elements at each round of factor analysis

\begin{tabular}{|c|c|c|c|c|c|c|}
\hline & Round 1 & Round 2 & Round 3 & Round 4 & Round 5 & Round 6 \\
\hline Data KMO & 0.772 & 0.778 & 0.814 & 0.805 & 0.804 & 0.812 \\
\hline Element & E23 & E3 & E15 & E32 & E17 & E21 \\
\hline Individual KMO & 0.342 & 0.413 & NA & NA & NA & NA \\
\hline Highest loading & NA & NA & 0.457 & 0.474 & 0.461 & 0.445 \\
\hline \multirow[t]{2}{*}{$\begin{array}{l}\text { Reason for } \\
\text { removal }\end{array}$} & $\begin{array}{l}\text { low } \\
\text { individual } \\
\text { KMO in the } \\
\text { anti-image } \\
\text { correlation } \\
\text { matrix }\end{array}$ & $\begin{array}{l}\text { low individual } \\
\text { KMO in the } \\
\text { anti-image } \\
\text { correlation } \\
\text { matrix }\end{array}$ & $\begin{array}{l}\text { low loading } \\
\text { on the } \\
\text { rotated } \\
\text { component } \\
\text { matrix }\end{array}$ & $\begin{array}{l}\text { low loading } \\
\text { on the } \\
\text { rotated } \\
\text { component } \\
\text { matrix }\end{array}$ & $\begin{array}{l}\text { low loading on } \\
\text { the rotated } \\
\text { component } \\
\text { matrix }\end{array}$ & $\begin{array}{l}\text { low loading } \\
\text { on the rotated } \\
\text { component } \\
\text { matrix }\end{array}$ \\
\hline & Round 7 & Round 8 & Round 9 & Round 10 & Round 11 & Round 12 \\
\hline Data KMO & 0.816 & 0.815 & 0.82 & 0.815 & 0.805 & 0.813 \\
\hline Element & E10 & E18 & E27 & E6 & E1 & E19 \\
\hline Individual KMO & NA & NA & NA & NA & NA & NA \\
\hline Highest loading & 0.467 & 0.491 & 0.493 & NA & NA & NA \\
\hline $\begin{array}{l}\text { Reason for } \\
\text { removal }\end{array}$ & $\begin{array}{l}\text { low loading } \\
\text { on the rotated } \\
\text { component } \\
\text { matrix }\end{array}$ & $\begin{array}{l}\text { low loading on } \\
\text { the rotated } \\
\text { component } \\
\text { matrix }\end{array}$ & $\begin{array}{l}\text { low loading } \\
\text { on the } \\
\text { rotated } \\
\text { component } \\
\text { matrix }\end{array}$ & $\begin{array}{l}\text { crossload on } \\
\text { two factors }\end{array}$ & $\begin{array}{l}\text { sole element } \\
\text { under F8 }\end{array}$ & $\begin{array}{l}\text { crossload on } \\
\text { two factors }\end{array}$ \\
\hline
\end{tabular}

Finally, in the 12th round, after the removal of all elements with insufficient correlation to the rest of the data, using the remaining 26 elements, a KMO value of 0.810 is obtained, as presented in Table 3 . This indicates that factor analysis is justified, and the number of underlying principal factors might indeed be fewer than 26 . For the remaining 26 elements, Bartlett's test of sphericity has been analyzed in order to confirm the factorability of an inter-correlation matrix among factors (Bartlett, 1950)

The measurement results of both Bartlett's test of sphericity and the KMO, which is given in Table 3, prove that the inter-correlation matrix is factorable. The KMO measure is high enough and Bartlett's statistic is significant. (Tabachnick and Fidell, 2012).

Table 3. KMO and Bartlett's Test for the final model after reductions

\begin{tabular}{cll}
\hline Kaiser-Meyer-Olkin Measure of Sampling Adequacy & \multicolumn{2}{c}{ Bartlett's Test of Sphericity } \\
\hline 0.810 & Approx. Chi-Square & 1147.367 \\
& D.f. & 325 \\
& Sig. & 0.000 \\
\hline
\end{tabular}

The resulting rotated component matrix, which reveals 7 composite principal factors, is presented in Table 4 . These factors explain $75.207 \%$ of the variation in the data as presented in Table 5. The resulting factors and their composition in terms of the original survey elements are presented in Table 6. 
Table 4. Final rotated component matrix after reductions

\begin{tabular}{lcrrrrrr}
\hline \multirow{2}{*}{ Element } & \multicolumn{7}{c}{ Component } \\
\cline { 2 - 8 } & 1 & 2 & \multicolumn{1}{c}{3} & \multicolumn{1}{c}{4} & \multicolumn{1}{c}{5} & \multicolumn{1}{c}{6} & \multicolumn{1}{c}{7} \\
\hline E35 & $\mathbf{0 . 8 7 7}$ & 0.206 & 0.108 & 0.024 & -0.021 & 0.093 & 0.119 \\
E37 & $\mathbf{0 . 8 2 4}$ & 0.221 & 0.119 & 0.242 & 0.089 & 0.116 & -0.027 \\
E36 & $\mathbf{0 . 8 1 0}$ & 0.100 & 0.213 & 0.181 & -0.005 & 0.143 & 0.129 \\
E34 & $\mathbf{0 . 7 8 2}$ & 0.186 & 0.309 & 0.120 & 0.202 & 0.164 & -0.067 \\
E33 & $\mathbf{0 . 7 7 7}$ & 0.178 & 0.290 & 0.163 & 0.212 & -0.140 & -0.019 \\
E38 & $\mathbf{0 . 6 8 2}$ & 0.280 & 0.156 & 0.388 & 0.244 & 0.060 & 0.072 \\
E12 & 0.039 & $\mathbf{0 . 8 5 8}$ & 0.047 & 0.104 & 0.001 & -0.018 & 0.103 \\
E13 & 0.242 & $\mathbf{0 . 7 5 7}$ & 0.179 & 0.104 & 0.207 & 0.167 & -0.061 \\
E11 & 0.225 & $\mathbf{0 . 7 4 0}$ & 0.101 & 0.058 & 0.165 & 0.113 & 0.226 \\
E14 & 0.224 & $\mathbf{0 . 7 0 1}$ & -0.038 & 0.240 & 0.173 & 0.092 & 0.078 \\
E16 & 0.307 & $\mathbf{0 . 6 1 1}$ & 0.244 & -0.005 & 0.095 & 0.222 & 0.062 \\
E25 & 0.229 & 0.254 & $\mathbf{0 . 8 4 0}$ & 0.139 & 0.046 & 0.057 & -0.052 \\
E24 & 0.278 & 0.037 & $\mathbf{0 . 7 8 9}$ & 0.179 & 0.097 & 0.034 & 0.062 \\
E26 & 0.390 & 0.068 & $\mathbf{0 . 7 1 0}$ & 0.395 & -0.050 & 0.205 & -0.056 \\
E20 & 0.416 & 0.267 & $\mathbf{0 . 5 3 6}$ & 0.114 & 0.306 & -0.075 & 0.333 \\
E30 & 0.163 & 0.168 & 0.052 & $\mathbf{0 . 8 6 9}$ & -0.010 & -0.120 & 0.053 \\
E29 & 0.100 & 0.141 & 0.189 & $\mathbf{0 . 8 5 3}$ & 0.124 & -0.035 & 0.083 \\
E31 & 0.268 & 0.127 & 0.149 & $\mathbf{0 . 6 5 0}$ & 0.035 & 0.209 & 0.012 \\
E28 & 0.223 & -0.095 & 0.440 & $\mathbf{0 . 5 7 8}$ & -0.013 & 0.328 & 0.072 \\
E2 & 0.135 & 0.044 & -0.055 & 0.060 & $\mathbf{0 . 8 0 7}$ & -0.085 & 0.127 \\
E5 & 0.013 & 0.197 & 0.123 & -0.029 & $\mathbf{0 . 7 0 5}$ & 0.145 & 0.163 \\
E7 & 0.301 & 0.273 & 0.163 & 0.164 & $\mathbf{0 . 6 5 1}$ & 0.235 & -0.154 \\
E22 & 0.242 & 0.274 & 0.027 & 0.111 & -0.089 & $\mathbf{0 . 7 5 1}$ & 0.261 \\
E8 & 0.045 & 0.182 & 0.174 & 0.001 & 0.414 & $\mathbf{0 . 7 2 4}$ & -0.109 \\
E9 & 0.104 & 0.200 & -0.115 & 0.184 & 0.083 & -0.019 & $\mathbf{0 . 8 2 2}$ \\
E4 & -0.028 & 0.104 & 0.429 & -0.075 & 0.210 & 0.287 & $\mathbf{0 . 6 3 2}$ \\
\hline & & & & & & &
\end{tabular}

Table 5. Eigenvalues of the final components and the total variance explained

\begin{tabular}{crrrrrrrr}
\hline & \multicolumn{3}{c}{ Initial Eigenvalues } & & \multicolumn{3}{c}{ Initial Eigenvalues } \\
\cline { 2 - 4 } Component & Total & \% of Variance & Cumulative \% & Component & Total & \% of Variance & Cumulative \% \\
\hline 1 & $\mathbf{9 . 7 6 7}$ & $\mathbf{3 7 . 5 6 6}$ & $\mathbf{3 7 . 5 6 6}$ & 14 & 0.371 & 1.426 & 92.097 \\
2 & $\mathbf{2 . 5 3 7}$ & $\mathbf{9 . 7 5 9}$ & $\mathbf{4 7 . 3 2 5}$ & 15 & 0.348 & 1.338 & 93.434 \\
3 & $\mathbf{1 . 7 7 9}$ & $\mathbf{6 . 8 4 4}$ & $\mathbf{5 4 . 1 6 9}$ & 16 & 0.299 & 1.151 & 94.585 \\
4 & $\mathbf{1 . 7 2 1}$ & $\mathbf{6 . 6 1 9}$ & $\mathbf{6 0 . 7 8 8}$ & 17 & 0.264 & 1.016 & 95.601 \\
5 & $\mathbf{1 . 4 1 2}$ & $\mathbf{5 . 4 2 9}$ & $\mathbf{6 6 . 2 1 7}$ & 18 & 0.222 & 0.853 & 96.455 \\
6 & $\mathbf{1 . 2 1 5}$ & $\mathbf{4 . 6 7 2}$ & $\mathbf{7 0 . 8 8 9}$ & 19 & 0.180 & 0.692 & 97.146 \\
7 & $\mathbf{1 . 1 2 3}$ & $\mathbf{4 . 3 1 8}$ & $\mathbf{7 5 . 2 0 7}$ & 20 & 0.147 & 0.564 & 97.710 \\
8 & 0.895 & 3.443 & 78.651 & 21 & 0.139 & 0.533 & 98.244 \\
9 & 0.773 & 2.973 & 81.624 & 22 & 0.120 & 0.462 & 98.705 \\
10 & 0.696 & 2.678 & 84.302 & 23 & 0.116 & 0.445 & 99.150 \\
11 & 0.642 & 2.469 & 86.771 & 24 & 0.098 & 0.378 & 99.528 \\
12 & 0.543 & 2.087 & 88.859 & 25 & 0.068 & 0.260 & 99.788 \\
13 & 0.471 & 1.812 & 90.671 & 26 & 0.055 & 0.212 & 100.000 \\
\hline
\end{tabular}


Table 6. Resulting factors and their composition

\begin{tabular}{lll}
\hline Factor & Name & Included elements \\
\hline F1 & ICO whitepaper & E33, E34, E35, E36, E37, E38 \\
F2 & Websites for finance news and ICO listings & E11, E12, E13, E14, E16 \\
F3 & ICO Project sector and founder & E20, E24, E25, E26 \\
F4 & ICO Project team & E28, E29, E30, E31 \\
F5 & Social media & E2, E5, E7 \\
F6 & Bitcoin Forum and P\&D opportunity & E8, E22 \\
F7 & Friends, relatives and colleagues & E4, E9 \\
\hline
\end{tabular}

Finally, we performed a reliability analysis for the factors using Cronbach's $\alpha$ coefficient, in order to evaluate their internal consistency. According to Nunnally (1994), factors whose alpha values are between 0.7 and 0.9 are considered as reliable. Hence, for the analysis results presented in Table 7, factors 1 through 5 can be accepted as reliable since they are in the correct range, for F6 and F7 alpha values are below the acceptable lower limit.

Table 7. Internal consistency of the factors

\begin{tabular}{cccccccc}
\hline & F1 & F2 & F3 & F4 & F5 & F6 & F7 \\
\hline Cronbach's $\alpha$ & $\mathbf{0 . 9 3 8}$ & $\mathbf{0 . 8 6 2}$ & $\mathbf{0 . 8 8 0}$ & $\mathbf{0 . 8 3 4}$ & $\mathbf{0 . 7 2 1}$ & 0.512 & 0.437 \\
\hline
\end{tabular}

The results of the analysis reveal five composite principal factors that determine the decision to invest in an ICO. The most important factor for ICO investment is the whitepaper, which is closely followed by websites for finance news and ICO listing. The third factor represents ICO project sector and founder characteristics while the fourth factor is ICO project team quality. The last primary factor represents social media in the form of Twitter, Slack and Reddit. These factors cumulatively explain $66.217 \%$ of the variance in the model.

As expected, when it comes to investment decision original source of information like the whitepaper, reputable and specialized websites and the quality of the project founder and team are considered as more relevant factors. The social circle has a significantly lower impact than initially expected.

\section{Conclusion}

ICO investment has become one of the most popular project finance and crowdfunding methods, thanks to successful project examples and vast media coverage. The highly volatile market for cryptocurrencies results in significant risks as well as great opportunities. In this research, we have tried to identify the principal factors that affect the decision to invest in an ICO.

We identified 38 potential ICO investment signals that represent a comprehensive list of elements that may influence an investor. In order to evaluate the impact of the selected elements, we have conducted an online survey that targets an international set of ICO investors and asks their opinion about each of the potential signals. Data collected has been analyzed using explanatory factor analysis. The factor analysis has exposed 26 relevant elements and 5 underlying composite principal factors. These five principal factors are the ICO whitepaper, websites for finance news and ICO listings, ICO project sector and founder, ICO project team and social media.

The obvious limitation of our study is fact that the number of respondents to our survey was limited by our choice to focus on respondents who have at least once invested in an ICO. While this choice has prevented various biases in the responses, the resulting dataset of 66 observations did not lend itself to elaborate modeling. A natural extention of this study would be a wider audience for the survey, including even some ICO founders and otherwise participants of the ICO process so that we can see if all stakeholders agree on what is the key to ICO success.

It is interesting to observe that even with such a limited dataset based on a survey of ICO investors our findings are consistent with a number of studies that examine datasets with a large number of individual ICO projects. These findings are in support of the recent literature where white paper and the background of the project founder are found to be important ICO success factors as in Howell et al. (2019) as well as important determinants of the amount of 
funds raised as in Fisch (2019). They are also consistent with the findings of Amsden and Schweizer (2018). Our findings on social media and the internet are also consistent with some recent studies like Perez et al. (2020) where social capital in the form of social media activity, official website visits, search traffic are found to be indicative of ICO performance.

Our analysis showed that the whitepaper, project sector and founder as well as the team are the most significant signals among all the potential signals. It seems that an innovative project in the correct sector combined with a sound whitepaper and a reliable project team tend to convince investors to make an investment in an ICO. Hence the main factors that influence the ICO investors are not all that different from the traditional investors.

Contrary to common belief, people do not trust their immediate circle of friends, colleagues, and relatives when it comes to investment decisions. However, they are influenced by specialized news websites and the opinions of mostly anonymous users they get exposed to in online messaging applications and social media platforms.

In conclusion, we believe this research can bring a new perspective to both investors and ICO founders about which signals to follow when deciding to invest in an ICO or to launch one. From the perspective of the ICO project founders, it proves that traditional factors like the sector, team, and whitepaper combined with innovative social media and community usage can provide a good advantage in attracting investors. From the perspective of the investors, following these signals can help to spot the next popular or potentially successful ICO.

\section{References}

Amsden, R., \& Schweizer, D. (2018). Are Blockchain Crowdsales the New 'Gold Rush'? Success Determinants of Initial Coin Offerings. https://doi.org/10.2139/ssrn.3163849

Barsan, I. M. (2017). Legal Challenges of Initial Coin Offerings (ICO) Revue Trimestrielle de Droit Financier $(R T D F), 3,54-65$. Retrieved from https://ssrn.com/abstract=3064397

Bartlett, M. S. (1950). Tests of Significance In Factor Analysis. British Journal Of Statistical Psychology, 3, 77-85. https://doi.org/10.1111/j.2044-8317.1950.tb00285.x

Boreiko, D., \& Sahdev, N. K. (2018). To ICO or not to ICO - Empirical analysis of Initial Coin Offerings and Token Sales. SSRN Electronic Journal. https://doi.org/10.2139/ssrn.3209180

Chuen, D. L. K. (Ed.) (2015). Handbook of Digital Currency: Bitcoin, Innovation, Financial Instruments, and Big Data. Singapore: Academic Press. https://doi.org/10.1016/C2014-0-01905-3

de Jong, A., Roosenboom, P., \& van der Kolk, T. (2018). What Determines Success in Initial Coin Offerings? SSRN Electronic Journal. https://doi.org/10.2139/ssrn.3250035

Fisch, C. (2019). Initial coin offerings (ICOs) to finance new ventures, Journal of Business Venturing, 34, 1-22. https://doi.org/10.1016/j.jbusvent.2018.09.007

Howell, S. T., Niessner, M., \& Yermack, D. (2019). Initial Coin Offerings: Financing Growth with Cryptocurrency Token Sales. The Review of Financial Studies. https://doi.org/10.1093/rfs/hhz131

Jaffe, J. (2018). Initial Coin Offerings, Explained. CNET. Retrieved from https://www.cnet.com/how-to/initial-coin-offerings-explained/

Li, T., Shin, D., \& Wang, B. (2019). Cryptocurrency Pump-and-Dump Schemes. SSRN Electronic Journal. https://doi.org/10.2139/ssrn.3267041

$\begin{array}{lllll}\text { Lisk. } & \text { (n.d.). Whitepapers } & \text { Explained. }\end{array}$ https://lisk.io/academy/blockchain-business/icos/whitepapers-explained

Nakamoto, S. (2008). Bitcoin: A Peer-to-Peer Electronic Cash System. Retrieved from https://Bitcoin.org/Bitcoin.pdf

Ozturkoglu, O., Saygili, E. E., \& Ozturkoglu, Y. (2016). A manufacturing-oriented model for evaluating the satisfaction of workers - Evidence from Turkey. International Journal of Industrial Ergonomics. https://doi.org/10.1016/j.ergon.2016.05.002

Sockin, M., \& Xiong, W. (2018). A model of cryptocurrencies. Princeton University WP. Retrieved from http://wxiong.mycpanel.princeton.edu/papers/Crypto.pdf .

Tabachnick, B. G., \& Fidell, L. S. (2019). Using Multivariate Statistics Title: Using multivariate statistics. Retrieved from https://lccn.loc.gov/2017040173n 
Willett, J. (2012). MasterCoin Complete Specification vs. 1.0 (First Complete Specification). Retrieved from https://sites.google.com/site/2ndbtcwpaper/

Woods, S. (2016). \#Sponsored: The Emergence of Influencer Marketing. University of Tennessee Honors Thesis Projects. Retrieved from https://trace.tennessee.edu/utk_chanhonoproj/1976

Zetzsche, D. A., Buckley, R. P., Arner, D. W., \& Föhr, L. (2017). The ICO Gold Rush: It's a Scam, It's a Bubble, It's a Super Challenge for Regulators. SSRN Electronic Journal. https://doi.org/10.2139/ssrn.3072298

\section{Copyrights}

Copyright for this article is retained by the author(s), with first publication rights granted to the journal.

This is an open-access article distributed under the terms and conditions of the Creative Commons Attribution license (http://creativecommons.org/licenses/by/4.0/). 